\section{CARBON EMISSIONS}

\section{From under the ice}

Biogeosciences https://doi.org/g8ns (2021)

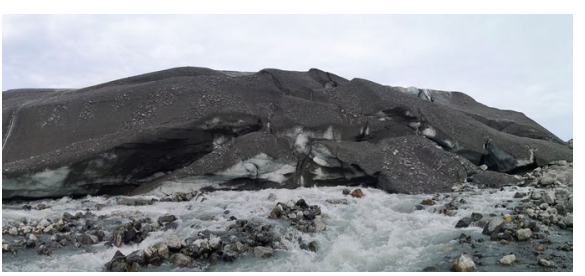

Credit: Sarah Elise Sapper.

The Arctic is warming rapidly, and thawing peatlands and permafrost are a potentially large source of GHG emissions to the atmosphere as frozen carbon is remobilized. Recently, meltwater from underneath the Greenland ice sheet has also been found to emit carbon in the form of methane and $\mathrm{CO}_{2}$. This is a previously unknown source of carbon emissions from the thawing Arctic, and the magnitude of these emissions and their likely impact on the climate are not clear.

To better constrain these emissions, Jesper Christiansen from the University of Copenhagen and colleagues measured methane and $\mathrm{CO}_{2}$ from subglacial meltwater in situ in the 2018 and 2019 melt season. They found gas concentrations in the meltwater and air were highly related, and the variability of gas concentrations in the air underneath the glacier was also related to meltwater runoff. The concentrations were highest at the start of the melt season, and isotopic measurements point to a microbial source for both the methane and $\mathrm{CO}_{2}$.
Overall, these results indicate that subglacial meltwater may be an important source of GHG emissions.

https://doi.org/10.1038/s41558-021-01257-6

\section{TRANSPORT MITIGATION}

\section{Sports league travel}

Environ. Sci. Technol. https://doi.org/g8nv (2021)

Sports leagues in North America generate massive emissions because they rely heavily on long-distance air travel throughout the season. Virtual solutions, adopted by many other sectors, are not feasible since players must be present for the game. However, the SARS-CoV-2 pandemic has unintentionally provided a chance for sports leagues to optimize the schedule and reduce emissions.

Seth Wynes of Concordia University, Canada, estimates that in the pre-pandemic 2018 season, teams from four major sports leagues of North America travelled 7.5 million kilometres and emitted 121,841 tonnes of carbon dioxide. The National Basketball Association (NBA) generates the highest emissions, as they travel with larger aircraft and have fewer consecutive games in the same arena.

The author further analyses the climate benefits that resulted from attempts to reduce exposure to the virus in the 2020 season. These interventions included geographic sorting, increasing consecutive repeated games, cancelling overseas games and reducing the season length. If these changes are maintained,

ATMOSPHERIC SCIENCE

Stretching the sky

Sci. Adv. 7, eabi8065 (2021)

The tropopause marks the upper bound of the lower atmosphere, the troposphere, and the start of the stratosphere. It is identified by the transition from decreasing to increasing temperatures in the atmosphere and is thought to be a sensitive indicator of climate change, with the tropopause height responding to temperature changes in the troposphere and stratosphere.

To understand recent changes, Lingyun Meng of Nanjing University, China, and a team of international collaborators use radiosonde balloon observations to show that there was a continuous increase in tropopause height throughout 1980-2020. The observations span from $20^{\circ} \mathrm{N}$ to $80^{\circ} \mathrm{N}$, and the authors find an increase of 50-60 metres per decade. Greenhouse gas emissions are driving accelerated warming in the troposphere, while reductions in the emissions of ozone-depleting substances cause weaker cooling of the stratosphere. This is particularly true for 2000-2020, for which the authors attribute the increased height primarily to anthropogenic warming in the troposphere. The earlier period, 1980-2000, had approximately equal contributions from the troposphere warming and stratosphere cooling. we could expect a reduction in air travel emissions of $22 \%$ in the future. Furthermore, these policies could also reduce player fatigue and injuries.

\section{FISHERIES CONFLICT}

\section{Whales in the way}

Proc. R. Soc. B Biol. Sci. https://doi.org/g8nz (2021)

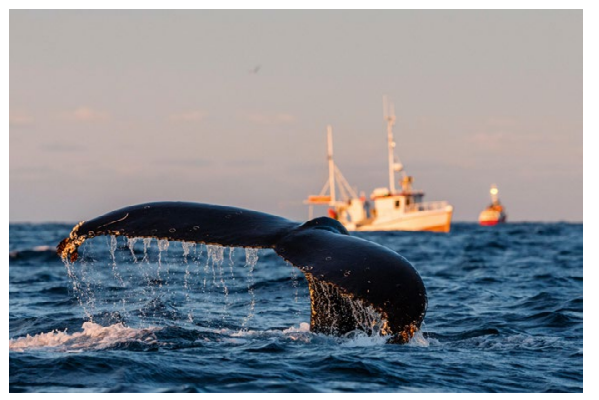

Credit: Nature Picture Library / Alamy Stock Photo

Marine heatwaves can have various direct and indirect effects on ocean wildlife, from thermal displacement and mass mortalities to the induction of pest or disease outbreaks. A 2014-2016 marine heatwave was also found to coincide with higher entanglement of endangered blue whales (Balaenoptera musculus) and humpback whales (Megaptera novaeangliae), leading to the suggestion that an under-examined impact of the heatwaves may include an increase in the frequency of human-wildlife conflicts.

To investigate this topic, Jameal F. Samhouri from the National Oceanic and Atmospheric Administration, USA, and colleagues in the USA combined dynamic whale distribution models and nearly 400,000 geolocations of fishing vessels to understand shifting whale entanglement risks in the context of an intense marine heatwave. The authors predicted increased whale presence within fishing grounds and two-to-threefold higher overlap between whales and fishing activity during the heatwave, a period associated with a nearly ninefold increase in entanglement reports. The application of various management strategies could not completely mitigate the risk, emphasizing the need for innovative management in the context of rapid environmental change.

TAM 